\title{
Understanding Datafication Effects of Open Government Information Systems - A Contemporary Systems Thinking Approach
}

\author{
Olivera Marjanovic \\ University of Sydney, Australia \\ olivera.marjanovic@sydney.edu.au
}

\author{
Dubravka Cecez-Kecmanovcic \\ University of New South Wales, Australia \\ dubravka@unsw.edu.au
}

\begin{abstract}
This paper contributes to an improved understanding of datafication effects of open government Information Systems (IS). We focus on a particular category of these IS that is designed to provide open performance data of a public sector (education, health, social services) in the name of accountability and transparency. While acknowledging possible positive datafication effects, in this paper we investigate the negative ones caused by propagation and reuse of open performance data. Using contemporary systems thinking as a theoretical lens, we identify three main types of datafication mechanisms, explain their underlying systemic manifestations and illustrate their societal effects. Drawing insights from a longitudinal research case study of a large-scale open government IS in Australia, we 'unpack' mutually-shaping relationships between technology and human behavior, reinforced by various feedback loops within a wider societal system.
\end{abstract}

\section{Introduction}

Datafication effects [1-4] are now permeating all areas of life and work in yet-to-be understood ways. New technologies make it possible to datafy i.e. convert to data, more digitized phenomena than ever before in human history [5]. In other words, "every click, every move has the potential to count for something, for someone somewhere somehow" [6:2]. While its effects could be positive [1], datafication may create serious negative and unintended consequences. "In a nutshell, the problem with 'datafication' is that 'somebody else may ... use the data thus produced often with purposes different from those originally intended" [3: II]. This is evident from many examples described in recent academic articles [1-3] and in popular press [7].

The negative effects of datafication are poorly understood $[1,3,8]$. As explained by Markus [8], most of the existing research on downside of datafication still focuses on threats to personal information privacy, information security and data-driven discrimination that may occur as a side effect (i.e. an unintended datafication effect) of customer segmentation and target marketing. Yet, these negative consequences are just a part of a much larger domain of often-invisible negative effects of datafication. "Clearly, a lot is at stake and our current understanding is limited... This gap calls for extensive research in information systems and neighboring disciplines" [1:154].

Focusing on this particular research gap, our paper has a dual objective. First, we aim to contribute to an improved understanding of datafication effects of government information systems (IS) that are designed to provide open data - here we term them open government IS. We focus on a particular type of these IS providing the so-called open performance data. Compared to other types of data that are more factual in nature, performance data are used to represent the performance of different public sectors (education, health, social services), typically in the name of accountability and transparency. These IS often create negative consequences [9]. In this paper we draw attention to this particular type of datafication because it affects both individuals and broader society, yet it is not sufficiently scrutinized for its social consequences [10]. Moreover, these systems and the performance data they provide are often perceived as objective and justified by the new public sector agenda of accountability and transparency $[11,12]$.

Our second research objective is to examine how these effects occur so they could be prevented or better mitigated. While they could be investigated from different perspectives (e.g. ethics, public policy), our particular focus is on data-related mechanisms.

Hence, we seek to address the following key research questions: What are possible datafication effects of open government IS designed to provide open performance data? How are these datafication effects created?

Using a theoretical lens of contemporary systems thinking, we demonstrate an innovative approach to analyzing various types of datafication mechanisms, 
their underlying systemic manifestations and wider consequences including negative societal effects. We ground our investigation and illustrate our approach by drawing from a large-scale case study of "My School" - a government IS designed to provide open performance data of almost 10.000 schools in Australia.

The paper is organized as follows. Section 2 summarizes relevant research, including related work on datafication and its societal consequences (both positive and negative) as well as open government IS. This is followed by an overview of systems thinking, including traditional and contemporary approaches (Section 3). The research context is presented in Section 4, followed by the research methodology described in Section 5. Section 6 presents research findings while Section 7 discusses the observed datafication mechanisms and their underlying systemic manifestations. Section 8 offers the main conclusions, study limitations and some ideas for future research.

\section{Background}

\subsection{The concept of datafication}

The term datafication was first proposed by MayerSchonberger and Cukier [5] in relation to big data. Thus, "to datafy a phenomenon is to put it in a quantified format so it can be tabulated and analyzed" [5:79]. Since then, datafication has been used by a growing group of researchers who investigate different aspects of propagation and use of different types of data, often in relation to the so-called big data. For example, Loebbecke and Picot use the term to describe "digitization and business analytics" [1] while Lycett [2] argues that "datafication is an information technology driven sense-making process" (p.384). Galliers et al. [3] discuss datafication in relation to data being propagated and used for the purposes other than those originally intended.

According to Lycett [2] datafication could be conceptualized by three key mechanisms of dematerialization, liquification and density. The concept of dematerialization relates to separation of the information aspect of an asset/resource and its use in context from its physical manifestation. The liquification concept is used to describe the fact that dematerialized data/information can be easily manipulated, combined, re-combined and moved around in ways that were not previously possible, owing to new IT infrastructures. The third concept density - is used to describe new forms of value creation made possible by data. To illustrate these key concepts Lycett [2] uses the case of Netflix. For example, in Netflix's streaming business model data is dematerialized by separation of content (asset) and information about its use (i.e. user's preferences). The liquification concept is illustrated by pervasiveness of personalized recommendation in the streaming model. Finally, dematerialization and liquification in combination enable a new ways of value creation that Lycett [2] terms "density". Thus, using years' worth of data on user behavior and preferences Netflix started producing its own content (e.g. remakes of popular series with the lead actors determined by customers' past preferences). Consequently, Netflix expanded its main business model from distributor of content provided by others to producer of its own content. However, Lycett [2] also offers the following warning "... it should be clear that datafication will unavoidably omit many features of the world, distort others and potentially add features that are not apparent in the first instance " (p.384).

When considered at the societal level, datafication is already creating significant changes for individuals and organizations $[1,10]$ - both positive and negative. Positive changes include growth of employment due to new online opportunities, increase in productivity and more value for consumers [1]. However, various datafication mechanisms continue to create negative and often unintended consequences, beyond commonly discussed privacy and security issues [8]. There is a gap in our current understanding of datafication mechanisms and effects $[1,3,8]$ that we intend to address in this research.

\subsection{Datafication and government IS}

Federal government bureaucracies are widely recognized as the most information-intensive organizations in the world [13]. When discussing the changes created by widespread use of data and analytics, Shirky argues that "the more an institution or industry relies on information as its core product, the greater and more complete the change will be" [14:107] When it comes to open data, government is expected to play several critical roles of a provider, catalyst, user and policy maker [15].

Government agencies around the world are already making data available in different forms and for different purposes. In this research we focus on a particular type of open data related to performance of individuals, organizations or whole industry/government sectors - often referred to as performance data. This type of data is increasingly made public by government IS, along with the simpleto-use tools to promote "inferability" - i.e. a citizen's ability to infer their own insights [11]. For example, using simple tools citizens can perform their own 
analysis of open data and help governments to identify waste and fraud in public spending [12].

In this research we are particularly interested in open data used to represent performance of individuals or organizations. A broader research area of performance data and their effects on individuals, organizations and society, has been investigated by numerous researchers beyond open data community. For example, prior studies in the pharmaceutical industry describe serious consequences of sharing performance data [16]. Other related studies show the effects of open performance targets in the UK public healthcare system [17] and the politics of performance data in a subsidized cultural sector [18].

We are particularly interested in possible issues created by open performance data in the education sector. Related studies are already being conducted all around the world, for example in UK [19], Denmark [20] and USA [21]. We aim to contribute to this important line of research, taking a novel systems perspective to investigate datafication mechanisms and their underlying systemic manifestations.

In summary, by drawing from the two domains of the literature, we can conclude that datafication effects of open data require further attention. By adopting a theoretical lens of systems thinking, we explore our research questions by investigating an example of government IS designed to provide open performance data from the Australian education sector.

\section{Systems thinking - traditional and contemporary approaches}

In general, a system is defined as "a set of elements or parts that is coherently organized and interconnected in a pattern or structure that produces a characteristic set of behaviors often classified as its function or purpose" [22:188]. Examples include biological, ecological, school system or even national economy. Systems thinking could be understood as an approach to understanding how components/things/elements influence each other through constant and dynamic interaction within a whole.

Systems thinking has a very long history and is widely practiced by many research disciplines. Within information systems (IS) discipline, which is primarily focused on technology-enabled systems, it is possible to observe the so-called hard (i.e. engineering-based) and soft approaches to systems thinking. The difference between the two is illustrated by Checkland's [23] examples: "Observer 1 (Hard) "I spy a system which I can engineer". Observer 2 (Soft) "I spy complexity and confusion; but I can organize exploration of it as a learning system" (p.18). A hard systems perspective avoids human issues and values and focuses on the mechanics of interaction among parts. In contrast, researchers such as Ulrich [24] practice (soft) systems thinking where the main focus is a social (rather than machine) system. Soft systems thinking is primarily concerned with system's purpose [24]. Consequently, Ulrich promotes thinking about different perspectives (purposes) of different stakeholders when attempting to solve systemic problems. Furthermore, Ackoff [25] considers a system to be "a whole that cannot be divided into independent parts" and consequently promotes systemic thinking about the whole (as opposed to analytical reductionalist thinking about parts).

In spite of its core concept being a system, in the IS discipline "systems" are often reduced to technical systems (i.e. software applications). In his influential paper provocatively titled "Desperately seeking systems in information systems" Alter [26] offers the following statement: "The information systems discipline is ostensibly about systems, but many of our fundamental ides and viewpoints are about tools, not systems" (p.757).

According to Senge [27] "systems thinking is a discipline for seeing wholes...a framework for seeing interrelationships rather than things, for seeing patterns of change rather than snapshots" (p.68). However relationships are not linear but constantly evolving through interdependent feedback loops. Going beyond individual components, "successful systems thinking is about being able to see the whole or context of a situation and its interconnection to its environment. Such a perspective enables unintended consequences of well-intended actions to be pre-empted and minimized" [28:20]. According to Chekland [23], systems are always an expression of an observer's viewpoint and therefore do not have an independent and verifiable existence. As discussed by Alter [26], this view of systems is very different form the ontological position of positivist research.

In our research we adopt the so-called contemporary systems approach to systems thinking and consider open government IS beyond its technical implementation of IS. This contemporary approach goes against reductionalist view of systems as assembly of components with predictable behaviour and outcomes that could be captured by precise models. Following Ackoff [25] we use a system as a way of seeing things as part of a wider process, interdependent, bounded for the observer's purposes.

Using contemporary systems thinking, we see an open government IS as fully embedded within a much wider societal system that is enacted through unfolding interactions of the technical component, government, users and society at large. As open data continue to be propagated and reused throughout the society, the 
boundaries of the "whole" societal system and its influence become very difficult, if not impossible, to determine in their entirety. Similarly, the behaviour of the 'whole' system is impossible to predict in its entirety because it is constantly unfolding through mutually shaping interactions.

Particularly relevant for our analysis is the view of systems by Meadows [22] which identifies the following basic system elements: Stock: an accumulation of material or information within a system (e.g. an interest-bearing saving account in a bank); Flows (to and from Stocks); and Feedback loops (reinforcing and balancing). Reinforcing feedback loops reinforce the direction of change and as such could lead to exponential growth. Balancing feedback loops on the other hand are equilibrating and as such could be a source of stability or a source of resistance. A key characteristic of any system is bounded rationality: "the logic that leads to decisions or actions that make sense within one part of the system but are not reasonable within a broader context or when seen as a part of the wider system" [22:187].

We conclude that systems thinking offers an opportunity to examine open government IS and their datafication effects, as intended in this paper. This line of thinking is inspired by previous recommendations for using systems thinking as a foundation for research into messy environments [29] and the net effects of digitization [1]. Further support for our approach could be found in recent research by Jetzek [30] who argues that societal challenges of open data demand "the system of systems approach" [30:91].

\section{Research context}

In this paper we focus on a web-based portal called My School as a prominent example of an open government IS designed to provide performance data on public education in Australia. Its main objective is to achieve transparency and accountability in the education sector, with the ultimate goal of improving students' educational outcomes. Currently in its eight year of operation, My School continues to provide performance data on almost 10.000 primary and secondary schools to the Australian public.

The My School portal was launched by the Australian Curriculum Assessment Report Authority (ACARA), in January 2010. However, the manual process of data collection started in 2008 when the first round of the so-called National numeracy and literacy (NAPLAN) test were administered to 3, 5, 7 and 9 year students. At that time, the results of NAPLAN tests were not open. Instead, teachers and schools received reports about their students' overall performance. At the same time, individual students' reports were sent to their parents. The same manual data collection process was repeated in 2009 .

In Jan 2010, the previously collected data about school performance were made available on the socalled My School government portal. Ever since, this portal has continued to publish open performance data of different schools in Australia to this day. Currently with 9 years of performance data (2008-2016), the My School portal (i.e. open government IS) is considered to be the most comprehensive source of school performance data in Australia [31].

In addition to public data, My School also provides easy-to-use tools enabling any (unregistered) user to search and compare various aspects of schools' performance over time. The results are shown in simple visual forms (e.g. geo maps) to facilitate better understanding. To enable meaningful comparison of data ACARA also developed a specialized financial methodology as well as the so-called Index of Community Socio-Educational Advantage, so that similar schools could be grouped together and compared ('likes with likes') [31].

My School is a suitable case for exploring our research questions. From the very beginning, My School has continued to exemplify the society-wide datafication effects. These effects continue to reconfigure relations among government, schools and citizens - all with numerous unintended consequences. Due to its unexpected and, in many cases unintended negative datafication effects for the intended beneficiaries (children, parents, teachers, and schools), My School was subjected to two Senate Inquiries, typically conducted for matters of national importance. This case is inviting researchers to explore its numerous effects that are very much systemic in nature and caused by propagation and reuse of open performance data (i.e. datafication effects). Another particularly attractive feature of the My School case is the public availability of high quality and very rich data sources, as described in the next section.

\section{Research methodology}

We examine our research questions through a longitudinal interpretive case study of the My School government IS, focusing on its widespread societal consequences. Our research methodology is informed by hermeneutics as both a philosophy and a methodology for analysing data (extracts of texts) and interpreting actions of different agents $[32,33]$. As we followed events and collected evidence from various public sources, at the same time we analysed and interpreted the growing empirical material. Our interpretation emerged gradually, through careful consideration of the growing number of actors 
(parents, children, teachers, school principals, government agencies, media, financial experts, researchers, politicians etc.) and their actions and reactions to different datafication effects. This interpretative process was iterative in a sense that understanding was constantly moving from the whole to the part and back to the whole - referred to as a hermeneutic circle [32, 33]. Our hermeneutic analysis eventually produced a rich picture of different views of datafication effects that could be attributed to My School. Most importantly, our hermeneutic analysis was explicitly aligned with the system approach we adopted, while being guided by our research questions.

Data collection for our project spans a period of over ten years. We have been collecting documents from 2006 when the first plan to administer NAPLAN test was announced to the Australian public. In addition to government data, we collected articles published by media outlets, video cases posted on various web sites (government, school principles' association, teachers' associations), blogs and twitter feeds as well as numerous published studies completed by researchers in other disciplines (such as public policy, social science, politics, education and so on). Our current data set consists of $400+$ documents and is growing by the day. Table 1 includes a selected sample of the most relevant documents we used in this paper.

Table 1. Data sources used in this project

\begin{tabular}{|c|c|}
\hline Source & Data collected \\
\hline $\begin{array}{l}1^{\text {st }} \text { Senate } \\
\text { Inquiry }\end{array}$ & $\begin{array}{l}\text { - } 268 \text { written submissions } \\
\text { - Interim report } \\
\text { - Transcripts of public hearing in } \\
\text { Canberra } \\
\text { - Final report } \\
\text { - Australian Government's Response to } \\
\text { the Senate }\end{array}$ \\
\hline $\begin{array}{l}2^{\text {nd }} \\
\text { Senate } \\
\text { Inquiry }\end{array}$ & $\begin{array}{l}\text { - } 93 \text { written submissions } \\
\text { - Interim report: The effectiveness of } \\
\text { NAPLAN } \\
\text { - Transcript of public hearing in } \\
\text { Melbourne } \\
\text { - Final report } \\
\text { - Australian Government's } \\
\text { Response to the Senate }\end{array}$ \\
\hline $\begin{array}{l}\text { Media } \\
\text { resources }\end{array}$ & $\begin{array}{l}\text { - over } 150 \text { articles from national } \\
\text { newspapers ( } 2006 \text { - to date) } \\
\text { - video clips broadcasted by national tv } \\
\text { channels and posted on My School }\end{array}$ \\
\hline
\end{tabular}

Data analysis was conducted through a number of hermeneutic circles. As we collected new documents we read and classified them according to the source, authority and medium, document purpose and related event, and the topics addressed. Within the selected documents, we coded sections of the text that refer to some important aspects of My School-created datafication effects and their reported impact. This analysis allowed us to explore, trace and crossreference numerous consequences of My School on different stakeholders, adopting a systemic view.

\section{Research findings - datafication effects}

Our research findings confirm ongoing datafication effects on students, parents, teachers, school principals and even wider society without any direct involvement in the education sector. It is also possible to observe that these effects started soon after the My School web portal went alive. For example, within hours of the performance data made available to public, Australian media were very quick to react to, and take advantage of them. They also become the strongest public advocates of transparency and accountability, by publishing their own (very crude) league tables ranking schools based on their performance. Arguing that their insights were legitimate and accurate (because they were based on official government data), Australian media even proclaimed their new role of "leading education revolution" and "becoming the voice of the public". [34, 35, 36, 37]. Even more, they also argued the case for making performance data open in other public sectors and services (including universities and hospitals), because consumers have a right to know which service providers are performing well [35].

However, within days of making school performance data open Australian media also started reporting on very serious negative effects and unintended consequences for parents, students, teachers, and school principles. As these effects were created by propagation and reuse of open data, they could be classified as datafication effects.

For example, many parents had difficulties dealing with serious consequences of data-reinforced perceptions. Some parents were stigmatized for not being able to offer "better education" to their children [36]. Informed by various league tables perceived to be objective, many parents started moving children from "bad schools" to better performing schools [36], creating more pressure for some public schools and further stretching their limited resources.

Parents also reported other negative consequences for their children including stress, anxiety, low selfesteem and discrimination [38, 39]. Even more, some parents started putting more pressure on teachers and school principals. Using school league tables, they started interrogating good teaching [38: 137].

"[T] eachers now had their reputations at stake and had been given an incentive to teach strong performers 
and gifted students, who are often clustered in classes, instead of being judged on the performance of lower achievers". [38, Submission 75].

In response, many teachers modified their practices and started "teaching to data" $[36,37]$. Furthermore, while many, if not most, teachers maintained their integrity, increasing numbers of teachers responded by "manipulating the data" [37, p.137]. For example, they were asking lower-performing students or recent migrants to stay at home and avoid the test $[36,38,39]$. Similarly, school principles also responded by enrolling better students, in order to maintain or increase their school's performance [38, 39].

All these negative consequences and effects prompted the First Senate inquiry in May 2010, less than 6 months after the launch of My School. Based on very substantive evidence, including public hearings and written submission, the First Senate inquiry confirmed the negative effect of publishing My School data on students, parents, teachers and schools. Consequently, the Senate Committee made a number of recommendations, however, most were related to technical features of My School, rather datafication effects.

However, the open performance data continued to create negative datafication effects, in spite of all improvements made in response to the First Senate Inquiry's recommendations. This prompted the Second Senate inquiry in 2014, followed by My School review in 2015. Our analysis of more recent documents confirmed that negative datafication effects not only persisted but even widened in scope beyond educational sector. For example, real-estate and financial advisors are now combining My School performance data with their own proprietary data to expand their services by offering advice about affordable properties in the vicinity of good schools (based on their My School ranking)., see for example [41]. Their reports also confirm the impact of school boundaries (as determined by My School) on realestate prices in Australia, thus illustrating further societal impacts of open data propagation and reuse.

Furthermore, leading national newspapers also started to replicate the My School portal by creating their own repositories of data fed from the official My School data. The most recent example of this replication is the so-called "Your School" web portal [42] set up by the Australian newspaper. The welcome statement on the Your School portal echoes the one from the government-owned My School portal: "Now in its fourth year, The Australian's Your School website has become an invaluable resource for parents weighing up the options for their children's education. Thousands of people have already used the interactive website to compare schools based on their performance, type and location." [42]

As open performance data continue to be propagated and reused further and further away from its source, their original meaning - literacy and numeracy test results - appears to be forgotten along the way. Instead public attention is turned to their (re)interpretations by a wider and wider group of stakeholders. Thus schools are labeled as "good", "bad", "poor" (in relation to school funding), "good value for money" (in relation to neighboring realestate). Similar interpretations are used for teachers e.g. "lead teacher" (in relation to their My School performance. However, the original and the main purpose of making school performance data open in order to improve school and student performance is yet to be attained, as reported:

"NAPLAN test results that were released this morning showed that in the seven years since the tests were introduced in primary and high schools, most measurements show no major improvement" [40, p.1].

While datafication effects are relatively easy to observe, the underlying mechanisms creating those effects are not well understood. In the following section we respond to these concerns and answer our research questions by drawing from the theoretical lens of systems thinking.

\section{Discussion}

Figure 1 depicts the overall system prior to the introduction of the My School web portal. Looking from the systems perspective, it shows a stock of internal data, which were collected, processed and stored by ACARA, inflows from Schools and outflows to Schools and parents. Prior to My School introduction, all schools received only their own performance data for the purposes of feedback and improvement. The overall system was regulated by various balancing (-) feedback loops from the government to the schools and the whole education sector. Examples of those include government policies and funding. However, the inner working of this system was very much invisible to the wider society.

Figure 2 depicts the overall system after my School introduction. It shows the emergence of numerous feedback loops, both reinforcing $(+)$ and balancing (-), and resulting from open performance data and league tables. For simplicity Figure 2 shows only a sample of these feedback loops. For example, new reinforcing feedback loops emerged from the public, parents, politicians and media to schools and teachers. The existing feedback loop from the government to the education sector was strengthened with more pressure 
put on schools, as funding was now linked to My School performance.

As datafication effects continued with new feedback loops being created and the existing ones being strengthen, the Australian government reacted by conducting two Senate inquiries and, more recently a major review. Looking form the systems perspective these government "interventions" could be seen as 'balancing' (-) feedback loops.

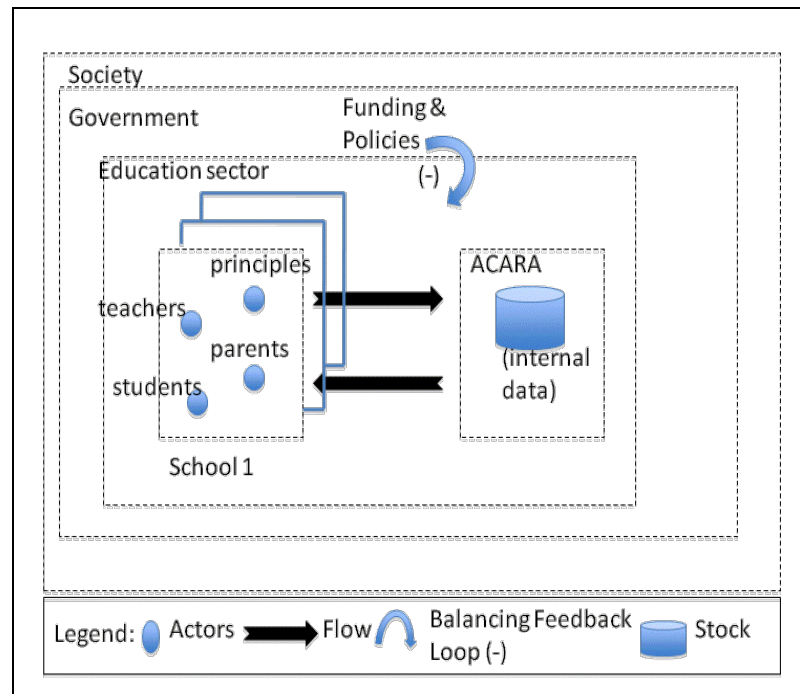

\section{Figure 1. The overall system prior to My School introduction}

However, with performance data being further propagated, reused and reinterpreted, the boundaries of the original system (i.e. open government IS) continued to expand. The original system (Figure 1) included actors who were directly involved in public education. With performance data published and propagated, a growing group of actors (media, politicians, property advisors) were joining and expanding the system though their data-informed actions. The original system' stock (i.e. the My School portal) was also replicated with media creating their own new versions of stock (i.e. repositories of data) using the My School data. Given the reported impact of My School data on real-estate prices in Australia, we can observe that the boundaries of the current system have expanded to include the whole society.

Table 2 offers a summary of our findings, including our responses to the stated research questions. Thus, in response to the first research question, we confirm that open performance data do create serious unintended and often hard-to-predict negative datafication effects for a wide group of actors well beyond the education system. We also observe that these datafication effects were propagated and even reinforced by widening feedback loops triggered by reinterpretation and use of data.

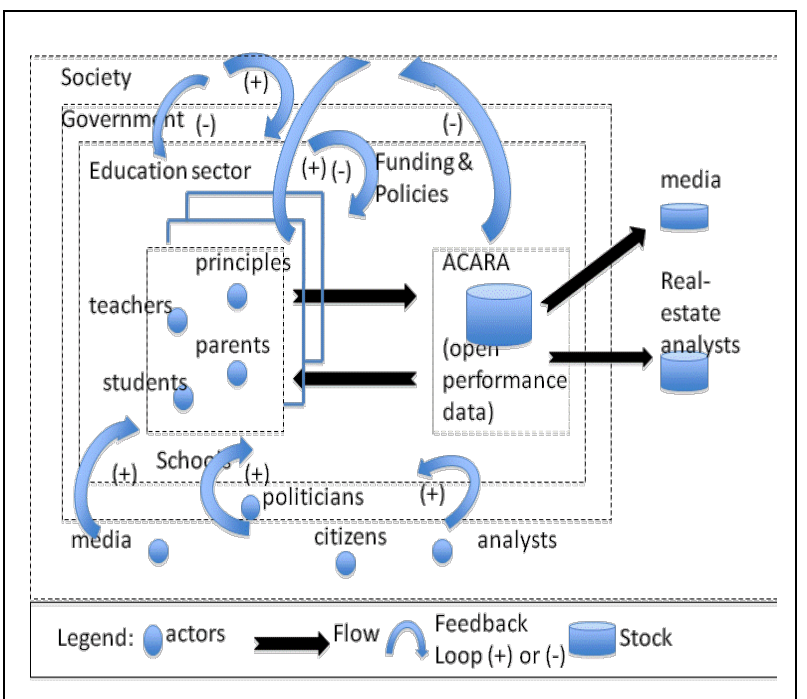

\section{Figure 2. The overall system after My School introduction}

To answer the second research question, we use systems thinking to analyze how these datafication effects occur. As shown by Table 2, we have identified the three main datafication mechanisms. The first two include dematerialization, liquification, as previously defined by Lycett [2]. As for the third mechanism, we renamed the concept of "density" Lycett [2] to the more appropriate (i.e. precise) "strategizing" to indicate that value creation was achieved by individual actors reinterpreting and reusing data strategically i.e. in pursuit of their individual goals.

We also observe that these datafication mechanisms are not independent but are highly related. Thus, a recombination of data to create new meaning (liquification) is made possible by dematerialization. Similarly, as data continue to be reinterpreted, further actions taken by actors in pursuit of their own goals include strategic (i.e. goal-driven) liquification of dematerialized data.

Furthermore, in case of open government IS designed to make performance data available to public, we notice an important and even harmful trend that could be best described as "transfer" of legitimacy. For example, when performance data is dematerialized, legitimacy of the system's stock (data published on web portal) is then taken to legitimize any information derived from the data (e.g. it is based on government data - therefore is legitimate and true). 
Table 2. The observed datafication mechanisms, their effects and systemic manifestations

\begin{tabular}{|l|l|l|l|}
\hline $\begin{array}{l}\text { Datafication } \\
\text { mechanisms }\end{array}$ & Example & $\begin{array}{l}\text { Datafication effects } \\
\text { (Research question 1) }\end{array}$ & $\begin{array}{l}\text { Underlying systemic } \\
\text { manifestations } \\
\text { (Research question 2) }\end{array}$ \\
\hline $\begin{array}{l}\text { Dematerialization } \\
\text { (separation of } \\
\text { physical data } \\
\text { from information) }\end{array}$ & $\begin{array}{l}\text { Media asserting } \\
\text { their data analysis } \\
\text { (e.g. league tables) } \\
\text { as "legitimate" }\end{array}$ & $\begin{array}{l}\text { Legitimacy of the stock (physical } \\
\text { aspect of data), misused to } \\
\text { legitimize derived information }\end{array}$ & $\begin{array}{l}\text { Data stored in Stock separated } \\
\text { from information i.e. meaning as } \\
\text { inferred by different human } \\
\text { actors in the system. }\end{array}$ \\
\hline $\begin{array}{l}\text { Liquification } \\
\text { (recombination of } \\
\text { data to create new } \\
\text { meaning) }\end{array}$ & $\begin{array}{l}\text { Recombination of } \\
\text { My School data } \\
\text { with financial and } \\
\text { real-estate data, } \\
\text { used by industry } \\
\text { based analysts }\end{array}$ & $\begin{array}{l}\text { Real-estate prices affected by the } \\
\text { quality of schools (as represented } \\
\text { by My School portal) }\end{array}$ & $\begin{array}{l}\text { Open stock created opportunities } \\
\text { for unrestricted out flows, to be } \\
\text { combined with other stock }\end{array}$ \\
\hline $\begin{array}{l}\text { Strategizing } \\
\text { (recombination of } \\
\text { data and other } \\
\text { resources in } \\
\text { pursuit of } \\
\text { individual actors" } \\
\text { goals ) }\end{array}$ & $\begin{array}{l}\text { - Media creating } \\
\text { their own web } \\
\text { portals in order to } \\
\text { attract readers and } \\
\text { improve revenue } \\
\text { streams } \\
\text {-Schools keeping } \\
\text { under-performing } \\
\text { students at home to } \\
\text { improve test } \\
\text { results. }\end{array}$ & $\begin{array}{l}\text { - Media assuming the voice of } \\
\text { new education revolution, } \\
\text { increasing public pressure on } \\
\text { teachers, students, parents and } \\
\text { principles } \\
\text { - New behaviors emerging to } \\
\text { comply with the data (e.g. } \\
\text { teaching to test) }\end{array}$ & $\begin{array}{l}\text { - Replication of stock which is } \\
\text { neither regulated nor scrutinized } \\
\text { but claimed to be legitimate } \\
\text { - Use of feedback loops to } \\
\text { influence the system in pursuit of } \\
\text { individual goals. } \\
\text { - Bounded rationality of } \\
\text { individual actors }\end{array}$ \\
\hline
\end{tabular}

Moreover, the subsequent liquification of data, where these "legitimate" information flows are further combined and recombined in different contexts and for different purposes, continues to carry "legitimacy" even though the resulting information is further away form physical data.

The proposed concept of data-driven strategizing in pursuit of individual goals can be also explained using systems thinking, in particular the concept of "bounded rationality". Pursuit of individual goals within the system destabilizes it, leading to "policy resistance" [22]. Thus, "Policy resistance comes from the bounded rationalities of the actors in a system, each with his, her (or "its" in case of an institution) own goals... Such resistance to change arises when goals of subsystems are different from and inconsistent with each other" [22, p.113].

We observe that this particular use of data from open sources that carries "legitimacy" offers further opportunities to individuals and organizations with resources and "know-how" to use public data in pursuit of their own goals. However, these goals could be in a direct conflict with the goals of other actors in the system. Consequently, all identified datafication mechanisms and their corresponding systemic manifestations require very careful consideration of possible ethical issues.

\section{Conclusions, limitations and future work}

Government IS designed to make performance data public are very complex systems and their farreaching societal consequences and effects are hard to predict at the time of their design and implementation. In this paper we offer a contemporary systems thinking approach as a possible conceptual tool that could be used by designers and managers of these systems as well as all stakeholders who might be impacted these systems.

As shown by our research, systems thinking is important and needed. "Much has been written about IS-related disappointment and failures. Is there evidence that inadequate systems thinking contributes substantially to the problem?" [26:766].

By combining the recent research on conceptualization of datafication mechanisms with contemporary systems thinking, we advance the field by providing an improved understanding of the underlying systemic issues of the wider societal system within which the government IS operates. More specifically we find that the systemic issues of making system's stock available to public, replicating 
the stock, allowing additional reinforcing feedback loops and not managing the balancing feedback loops - all contribute to datafication mechanisms of dematerialization, liquification and strategizing. In turn, these mechanisms result in harmful effects for all stakeholders (intended and unintended).

In terms of practical contributions, we offer an idea of using contemporary systems thinking to guide the stakeholders' engagement with the overall (holistic) system in a way that would provide a shared language and common foundations for discussion of different perspectives. Our future work includes articulation of a set of principles to guide ongoing engagement with this type of open government IS. We see this as an exciting opportunity for future multidisciplinary research on open government IS and their datafication effects as these systems are here to stay.

\section{References}

[1] Loebbecke, C. and Picot, A. 2015. "Reflection on societal and business model transformation arising from digitization and bog data analytics: A research agenda". Journal of Strategic Information Systems, 24. p. $149-157$.

[2] Lycett, M. 2013. “ Editorial: 'Datafication': making sense of (big) data in a complex world". European Journal of Information Systems, 22, p. 381-386.

[3] Galliers, R., Newell, S., Shanks, G., Topi, H. 2015. "Call for papers for the special issue: the challenges and opportunities of 'datafication': Strategic impacts of 'big' (and 'small') and real-time data - for society and for organizational decision makers". Journal of Strategic Information Systems, 24, II-III.

[4] Newel, S. and Mirabelli, M. 2015. "Strategic opportunities (and challenges) of algorithmic decisionmaking: a call for action on the long-term societal effects of 'Datafication", Journal of Strategic Information Systems, 24(1), p.3-14.

[5] Mayer-Schonberger, V., Cukier, K., 2013. Big Data: A Revolution That Will Transform How We Live, Work and Think. John Murray Publishers. UK.

[6] Gitelman, L. 2013. Raw Data is an Oxymoron. MIT Press. Cambridge. MA.

[7] Pettypiece, S. and Robertson, J. 2014. "Hospital are mining patients' credit card data to predict who will get sick”, Bloomberg Business week, July 03, 2014.

[8] Markus L. 2015. "New games, new rules, new scoreboards: the potential consequences of big data". Journal Information Technology, 30, pp. 58-59.
[[9] Bevan, G. 2006. "What's Measured Is What Matters: Targets and Gaming in the English Public Health Care System". Public Administration, 84(3), p.517-538.

[10] Zuboff, S. 2015 "Big other: surveillance capitalism and the prospects of an information civilization", Journal of Information Technology, 30, p.75-89.

[11] Michener, G. and Bersch, K. 2013. "Identifying transparency". Information Polity. 18, p.233-242.

[12] Lourenco, R.P. 2013. "Data disclosure and transparency for accountability: A strategy and case analysis" Information Polity 18, p.243-260.

[13] Kraemer, K.L., Dickhoven, S., Tiemey, S.F., King, J. L., 1987. Datawars: The Politics of Modeling in Federal Policymaking, Columbia University Press.

[14] Shirky, C. 2008. Here comes everybody: How change happens when people come together. Penguin Books, London.

[15] Manyika, J., Chui, M., Groves, D., Farrell S. et al. 2013. Open Data: Unlocking innovation and performance with liquid information, The McKinsey Global Institute.

[16] Dambrin, C. and Robson, K. 2011.'Tracing Performance in the Pharmaceutical Industry: Ambivalence, Opacity and the Performativity of Flawed Measures", Accounting Organization and Society, (36), p.428-455.

[17] Bevan, G. 2006. "What's Measured Is What Matters: Targets and Gaming in the English Public Health Care System". Public Administration, 84(3), p.517-538.

[18] Selwood, S. 2009. "The Politics of Data Collection: Gathering, Analysing and Using Data about the Subsidized Cultural Sector in England". Cultural Trends 12(47), p.13-84.

[19] Smith, P. 1995. "On Unintended Consequences of Publishing Performance Data in the Public Sector", International Journal of Public Administration. (18, 2\&3), pp.277-310.

[20] Henriksen, H.Z., Andersen, K.N. and Medaglia, R. 2011. "Public sector IS maturity models: legal pluralism invades public schools". Electronic Government. Springer Berlin Heidelberg, p.100-111.

[21] Jacob, B.A. and Levitt, S.D. 2003. Rotten apples: an investigation of the prevalence and predictors of teacher cheating". The Quarterly Journal of Economics. August 2003. p.843-877. 
[22] Meadows, D.H. 2008. Thinking in Systems: A Primer, Chelsea Green Publishing, White River Junction, Vermont.

[23] Checkland, P. 1999. Systems thinking, systems practice, John Wiley \&Sons, Chichester, England.

[24] Ulrich, W. 1983. Critical Heuristics of Social Planning: A New Approach to Practical Philosophy. Bern, Haupt.

[25] Ackoff, R. 1981. Creating the Corporate Future: Plan or be Planned for. John Wiley \& Sons, NY.

[26] Alter, A. 2004. "Desperately Seeking Systems Thinking in the Information Systems Discipline". ICIS 2004 Proceedings. Paper 61.

[27] Senge, P. 1990. The Fifth discipline: the Art and practice of the Learning Organization, Doubleday/Currency, New York.

[28] Wolstenholme, E.F. 2003. "A core set of archetypal Structures in Systems Dynamics", System Dynamics Review, 19(1), p.7-26.

[29] Taylor, D. 2003. "Improving the design of aged care accreditation standards using contemporary systems thinking concepts". AMCIS 2003 Proceedings, Paper 361 .

[30] Jetzek, T. 2016. "Managing complexity across multiple dimensions of liquid open data: The case of the Danish basic data program", Government Information Qtrly, 22, p.89-104.

[31] ACARA, 2016. CEO Report: My School, May 2016, http:/www.myschool.com (accessed 27 Aug 2016).

[32] Gadamer, H. 1960. Truth and Method, New York: Continuum.

[33] Crotty, M. 1998.. The Foundations of Social Research - Meaning and Perspective in the Research Process, Allen \& Uniwin.

[33] Klein, H. and Myers, M. 1999. "A Set of Principles for Conducting and Evaluating Interpretive Field Studies in Information Systems" MIS Quarterly 23(1), p. 67-94.
[34] Canberra Times Editorial. 2010. "The test results will hit the fan this week". Canberra Times, January 25, 2010, p.12.

[35] The Australian Editorial, 2010. "Accountability is essential to improve all our schools". The Australian, May 1.p. 15.

[36] Wyn, J., Turnbull, M., Grimshaw, L. 2014. The Experience of Education: The Impacts of high stakes testing on School Students and their Families: A Qualitative Study. The Whitlam Institute, University of W. Sydney.

[37] Thomson, G. and Cook, I. 2013. "Manipulating the Data: Teaching and NAPLAN in the Control Society". Discourse: Studies in the Cultural Politics of Education, 35(1). p.129-142.

[38] The Australian Senate. 2010. Final report: Education, Employment and Workplace Relations References Committee: Administration and reporting of NAPLAN testing, Nov.

[39] The Australian Senate. 2014. Final report: The Senate: Education and Employment Reference Committee: Effectiveness of the National Assessment Program Literacy and Numeracy, March.

[40] Brennan, B. 2015. "NAPLAN results: Annual numeracy and literacy report shows 'limited' significant improvement in students' skills", ABC News online transcript, Wed 5 Aug 2015.

[41] PropertyValue, 2016. Upgrade to premium to view NAPLAN and ICSEA scores, fees and funding. http://www.propertyvalue.com.au. (accessed 26 Aug 2016).

[42] The Australian. 2016. Your School, available from http://www .theaustralian.com.au/national-affairs/indepth/schools/interactive\#search 